\title{
ENTREPRENEURSHIP IN AN EMERGING AND CULTURALLY DIVERSE EConomy: A South African Survey of Perceptions
}

\author{
John Luiz
}

Wits Business School, University of the Witwatersrand

Martine Mariotti

Research School of Economics, Australian National University

Accepted January 2011

\begin{abstract}
South Africa has consistently ranked very poorly in the Global Entrepreneurship Monitor survey in terms of entrepreneurial activity. It is clear that South Africa is not producing a sufficiently entrepreneurial economy and this needs to be addressed so as to create employment, expand markets, increase production and revitalize communities. This paper examines the entrepreneurial traits of a diverse group of young adults in South Africa. It draws on a sample of 609 university students and looks at their attitudes towards and perceptions of entrepreneurship, entrepreneurial opportunities and the broader economic environment in an attempt to clarify how South Africans view entrepreneurship. Although the data do not allow the identification of causal relationships, descriptive statistics show that socio-economic elements play a noteworthy role in people's perceptions of the value of entrepreneurship and thus need to be incorporated in entrepreneurial models.
\end{abstract}

Key words: entrepreneurship, entrepreneurial traits and process, Global Entrepreneurship Monitor, employment, socio-economic, demographics, South Africa

JEL: J00, O17, 55, Z13

\section{1}

\section{Introduction}

The role of entrepreneurship in economic processes is well documented (see Naude, 2011 for a more complete discussion). Van Praag and Versloot (2007:352), on an analysis of 57 recent studies, conclude that entrepreneurs have a very specific function in the economy: they create employment and productivity growth, and produce and commercialise high-quality innovations. Entrepreneurial firms also create important spill-overs that affect regional employment growth rates in the long term. Ayyagari, Beck and Demirguc-Kunt (2007:429) in a study of 76 countries find that on average SMEs constitute 64 per cent of the economy while the informal economy on average accounts for 26 per cent of GDP in their sample of developed and developing countries. Therefore, understanding the drivers of entrepreneurial behaviour at both a macro/institutional level as well as at a micro/individual level is an important area for research within the social sciences.

South Africa has one of the highest unemployment rates recorded internationally 25.3 per cent in the third quarter of 2010 (Statistics SA, 2010). Given this high unemployment rate, Kingdon and Knight (2004:392) argue that one would expect a large informal sector to absorb this surplus labour, but South Africa has a relatively small informal sector. There are a number of possible explanations for this phenomenon (see Banerjee, Galian, Levinsohn, McLaren \& Woolard, 2008; Rodrik, 2008) but a recurring theme is the assertion that South Africans lack entrepreneurial spirit. The South African government has implemented various strategies to encourage entrepreneurs and small businesses without much success (see Herrington, Kew \& Kew, 2009; Urban, 2010 
for a full discussion). South Africa performs very poorly in international entrepreneurship surveys and has consistently been ranked near or at the bottom in the Global Entrepreneurship Monitor (GEM) (Bosma \& Levie, 2009:21). Undoing the legacy of apartheid necessitates bringing more South Africans into the economic mainstream but the large corporate sector cannot absorb the surplus labour which means that entrepreneurial activity must be an important cornerstone of any economic strategy. Understanding the drivers of entrepreneurship in South Africa is thus an important area for research.

This paper examines the entrepreneurial traits of a diverse group of young adult university students in South Africa drawing on a sample of 609 respondents. It looks at their attitudes towards and perceptions of entrepreneurship, entrepreneurial opportunities and the broader economic environment. The aim of the study is to explore the impact of socio-economic, demographic, cultural and institutional variables on entrepreneurial attitudes of individuals. Although the data do not allow the identification of causal relationships, the results suggest that socioeconomic factors play a significant role in entrepreneurial behaviour and thus need to be accounted for in entrepreneurial models.

The paper is structured as follows. Section 2 , the literature survey, explores the concept of entrepreneurship and the explanations for entrepreneurial activity with a particular focus on the South African performance in the latter part of the section. This is followed by an explanation of the methodology employed, in Section 3. Section 4 presents the results of the survey and an analysis in terms of the socioeconomic, demographic and institutional characteristics of the respondents. Section 5 concludes.

\section{2}

\section{Literature review}

\subsection{Entrepreneurship, culture and individuals}

The research on entrepreneurship is rich and complex. Indeed merely defining entrepreneurship has spawned a mass of literature (see Schumpeter, 1934; Leff, 1979; Morrison, 2000; Kuratko \& Hodgetts, 2001). There are broadly two distinct approaches to defining this concept. The first approach focuses on the entrepreneurial process whilst the second approach emphasises the characteristics of the entrepreneur (see Carton, Hofer \& Meeks, 1998). Neither of these approaches is particularly satisfactory, because they should not be mutually exclusive. This paper defines the concept using both approaches, that is, a combination of the entrepreneurial process and the characteristics embedded within the entrepreneur and the society. In this vein, Ahwireng-Obeng (2006) examines three broad theoretical approaches to the supply of entrepreneurship - the sociopsychological, the socio-cultural, and the economic approaches:

\section{a) The socio-psychological approach}

Most discussions in this area of study usually begin with the work of Max Weber in his famous exposition of "The Protestant Ethic and the Spirit of Capitalism" in which he attempted to establish that the protestant ethic or the 'minor virtues' of thrift, hard work, sobriety, honesty and fulfilment of promises contributed to the successes of capitalist institutions in fostering fast economic progress brought about by a new character type.

\section{b) The socio-cultural approach}

This approach views entrepreneurship as an aspect of cultural change comprising the transformation of human agents and the socioeconomic setting in which they operate. It examines present and past political, social and economic institutions, their relationships with current values, motivations and incentives, and their conditioning effect on current role structures.

\section{c) The macroeconomic approach}

In the construction of a macroeconomic model of entrepreneurship, an identification problem emerges regarding the distinction between supply and demand determinants. It is normal practice to make the supply schedule a function of socio-psychological and cultural variables as well as the stock of human capital of the individual. The demand for entre- 
preneurship then becomes a function of demand for entrepreneurial goods and services which, in turn, depends on prices of production factors, the stock of existing and transferable technology and consumer incomes among others. The macroeconomic approach, therefore, incorporates both quantifiable and qualitative variables of both economic and non-economic description and is the tool of analysis widely used by development economists.

This paper uses an eclectic approach and explores perceptions amongst young South African adults both regarding the process of entrepreneurship and the traits of the entrepreneurially inclined. With regard to the characteristics of the entrepreneurs, it follows the literature which finds the following traits most pervasive: desire to be independent, locus of control, creativity, risk-taking propensity, need for achievement, and credible role models (see Carton et al., 1998). The paper analyses responses against individual and socio-cultural criteria such as race, gender, family history and other background information to examine the influence of these on entrepreneurial behaviour. Urban (2008:169-170) states that entrepreneurial motivation is likely to be conceptualised as a function of not only culture and personality, but also of the interaction between these, and proposes the following model:

$$
\mathrm{E} / \mathrm{P}=\mathrm{a}+\mathrm{bM}(\mathrm{C} \times \mathrm{P})[(\mathrm{cE} / \mathrm{S} \times \mathrm{dB} / \mathrm{S})]
$$

Where entrepreneurial performance $(\mathrm{E} / \mathrm{P})$ is a function of culture $(\mathrm{C}) \mathrm{x}$ personality $(\mathrm{P})$, and where both are treated as essential elements of entrepreneurial motivation.

Most studies examining the link between cultural variables and entrepreneurship are based on country level not individual level intercorrelations. For example, Hayton, George and Zahra (2002), Davidson and Wiklund (1997), Mueller and Thomas (2000) find links between national rates of innovation or entrepreneurial orientation with cultural variables such as individualism and power distance. This study attempts to look at potential variables affecting entrepreneurial attitudes both of an individual and cultural/social/institutional nature. South Africa is an interesting case to examine, because of its past structure of institutionalised racial estates which allows the examination of the interplay between the individual and social characteristics. For example, are there differences in attitudes based on race (given the process of racial discrimination in the past) or indeed are there intra-racial differences based on language, religion or parental status? In this respect South Africa provides a unique canvass to explore these issues.

\subsection{Entrepreneurship in South Africa}

The challenges facing South Africa are immense: it is a relatively young democratic, highly inegalitarian country, with enormous socio-economic problems. Jobs are not being created in the South African labour market at a fast enough rate and there is an expectation from school-leavers that they must find work in the corporate world with scant attention given to creating their own businesses. Banerjee et al. (2008:717) sees several reasons why unemployment has remained at such high levels. First, job search appears to be less effective for African job seekers compared to whites, which is likely due to the spatial separation between the business centres and the outlying areas where Africans reside. Second, while it may be expected that the informal sector will provide employment, especially in these outlying areas, and absorb many who would otherwise be unemployed, it has not. Unlike other African countries, the informal sector has grown very little as participation and unemployment rates have risen. They go on to state that crime rates and high start-up costs for small businesses probably impede its growth. Small, Medium and Micro Enterprises (SMMEs) are an important source of employment and economic growth in most countries and South Africa is lagging behind on this front. SMMEs make up 95 per cent of all corporations in Asia, employ up to 80 per cent of the labour force and constitute almost 60 per cent of Gross Domestic Product (GDP). In South Africa, SMMEs employ 47 per cent of the economically active population and constitute close to 45 per cent of GDP (DTI, 2008).

The state of entrepreneurship and small business development in South Africa presents 
a picture of underperformance relative to other countries at similar levels of development. For example, the 2009 GEM research (Herrington et al., 2009:59-60) shows the following:

- South Africa's TEA ${ }^{1}$ rate of 5.9 per cent is significantly lower than the average for all efficiency-driven economies (11.2 per cent) as well as the average for all middle to low income countries (14.8 per cent). According to the GEM data, a country at South Africa's stage of economic development would be expected to have a TEA rate in the order of 13 per cent, more than double South Africa's actual rate.

- Latin American countries have a significantly favourable attitude towards entrepreneurship and score well above the average for efficiency-driven economies with respect to entrepreneurial attitudes and perceptions. South Africa scores below average for these indicators. In terms of perceived capabilities, South Africa has the third lowest score. The discrepancy in entrepreneurial attitudes and perceptions between South Africa and the efficiency driven Latin American economies is likely to contribute to the significant differences between their respective TEA rates.

- South Africa's nascent entrepreneurship rate of 3.6 per cent is below the GEM average of 5.9 per cent as well as the average for efficiency driven economies of 6.1 per cent. In terms of new firm activity South Africa ranked 40th out of the 54 countries, with a new business prevalence rate of 2.5 per cent. This is significantly lower than the average of 5.2 per cent for all GEM countries and 5.3 per cent for all efficiency-driven countries.

- In terms of established business activity South Africa ranked last out of the 53 countries, with an established business rate of only 1.4 per cent. The average for all GEM countries is 7.7 per cent while that for all efficiency-driven countries is 7.9 per cent - almost six times the rate for South Africa.

Banerjee et al. (2008:735) question why South Africa has such a small informal and entrepreneurial sector, why the transition between the informal and formal sectors is so rare, and why the spirit of entrepreneurship is poor? This study is an exploratory attempt to understand the more micro foundations of entrepreneurship in South Africa by examining attitudes towards and behaviours of entrepreneurship and their association with socio-economic, demographic and institutional factors.

\section{3}

\section{Methodology}

A study by Simmons (1998) in the United Kingdom found that almost 50 per cent of final-year undergraduates think that they may start up their own business in the future. Similarly leading business schools report that 40 per cent of their post-graduate students start their own venture within 10 years of graduating. In South Africa there is little, if any, comparable research despite the obvious need for this research. Burger, Mahadea and O'Neill (2004) and Louw, Van Eeden, Bosch and Venter (2003) represent some of the few studies that examine the entrepreneurial traits of South Africans. In terms of the factors investigated, these studies are limited and a larger list of criteria is employed in this study.

The survey instrument is based upon a similar one to the National Science Foundation Innovation Project at several South Dakota universities. The structured questionnaire comprised of 40 questions testing respondents' perceptions towards entrepreneurship using a five point Likert scale and 10 questions of a more social or demographic nature. The survey was conducted amongst 609 university students drawn from various parts of South Africa. The physical questionnaires were administered to students in their lecture venues at the conclusion of their lectures. Participation was voluntary and completely anonymous. Students completed the questionnaire in class in approximately 30-45 minutes and the results were then scanned electronically.

Since the survey is based on existing prior surveys and since the sample is drawn from a diversity of backgrounds with respect to race, gender, family history, and income status, which is discussed below, content validity is maintained. Furthermore, to ensure that the 
wording and instructions of the questionnaire were clear and understandable and that the study was reliable, a pilot study was run thereby maintaining construct validity.

The results are based on descriptive statistics derived from the sample. For all 40 questions, the mean response on the Likert scale was calculated. Comparisons were then made testing for significance in either a category's mean deviation from neutral, or the difference in the means of two categories with different backgrounds where the backgrounds are taken from the 10 social and demographic questions in the survey.

\section{4}

\section{Results of the survey}

Table 1 lists the characteristics of the respondents in the survey with regards to gender, race, level of study, parent characteristics and personal money experience. 52 per cent of the sample was male, 48 per cent female. Africans made up 54.7 per cent of the sample, followed by Whites at 31.4 per cent, Asians at 11.3 per cent and Coloureds at 2.5 per cent. As one would expect at a tertiary level, 61 per cent of respondents had parents with tertiary education, 16 per cent with matriculation, 13 per cent with some high school, 6 per cent only primary school and 4 per cent with no education ${ }^{2}$. Parental income was fairly evenly distributed: a third had monthly income in excess of R20,000; 20 per cent R10,001-R20,000; 15 per cent R5,001R10,000; 13 per cent R2,000-R5,000; and 19 per cent less than R2,000. Furthermore, 43 per cent of their parents own their own businesses. 78 per cent of respondents received pocket money whilst at school, 43 per cent had a job whilst at school, and 48 per cent had a job whilst at university.

Table 1

Respondent characteristics

\begin{tabular}{|c|c|c|}
\hline Demographic variables & $\mathbf{n}$ & $\%$ \\
\hline \multicolumn{3}{|l|}{ Gender } \\
\hline Male & 306 & 52.4 \\
\hline \multirow[t]{2}{*}{ Female } & 278 & 47.6 \\
\hline & 584 & \\
\hline \multicolumn{3}{|l|}{ Race } \\
\hline African & 324 & 54.73 \\
\hline White & 186 & 31.42 \\
\hline Asian & 67 & 11.32 \\
\hline \multirow[t]{2}{*}{ Coloured } & 15 & 2.53 \\
\hline & 592 & \\
\hline \multicolumn{3}{|l|}{ Degree } \\
\hline Commerce and law & 323 & 54.84 \\
\hline $\begin{array}{l}\text { Arts, humanities, social science and } \\
\text { education }\end{array}$ & 108 & 18.34 \\
\hline Science & 58 & 9.85 \\
\hline Engineering & 24 & 4.07 \\
\hline \multirow[t]{2}{*}{ MBA } & 76 & 12.9 \\
\hline & 589 & \\
\hline \multicolumn{3}{|l|}{ Parents own business } \\
\hline Yes & 243 & 42.71 \\
\hline \multirow[t]{2}{*}{ No } & 326 & 57.29 \\
\hline & 569 & \\
\hline \multicolumn{3}{|l|}{ Parents education } \\
\hline Tertiary education & 355 & 61 \\
\hline
\end{tabular}




\begin{tabular}{|c|c|c|}
\hline Matriculation & 95 & 16.32 \\
\hline High school & 77 & 13.23 \\
\hline Primary school & 33 & 5.67 \\
\hline \multirow[t]{2}{*}{ No schooling } & 22 & 3.78 \\
\hline & 582 & \\
\hline \multicolumn{3}{|l|}{ Pocket money at school } \\
\hline Yes & 446 & 77.57 \\
\hline \multirow[t]{2}{*}{ No } & 129 & 22.43 \\
\hline & 575 & \\
\hline \multicolumn{3}{|l|}{ Job while at school } \\
\hline Yes & 247 & 43.33 \\
\hline \multirow[t]{2}{*}{ No } & 323 & 56.67 \\
\hline & 570 & \\
\hline \multicolumn{3}{|l|}{ Job while at university } \\
\hline Yes & 274 & 47.82 \\
\hline \multirow[t]{2}{*}{ No } & 299 & 52.18 \\
\hline & 573 & \\
\hline \multicolumn{3}{|l|}{ Study business subjects } \\
\hline Yes & 349 & 61.55 \\
\hline \multirow[t]{2}{*}{ No } & 218 & 38.45 \\
\hline & 567 & \\
\hline \multicolumn{3}{|l|}{ Parents monthly income } \\
\hline Less than R2000 & 106 & 19.41 \\
\hline R2000-R5000 & 70 & 12.82 \\
\hline R5001-R10 000 & 80 & 14.65 \\
\hline R10 001 - R20 000 & 109 & 19.96 \\
\hline \multirow[t]{2}{*}{ Greater than R20 000} & 181 & 33.15 \\
\hline & 546 & \\
\hline
\end{tabular}

Table 2 presents summary statistics on all the perception questions provided in the survey ${ }^{3}$. Respondents were asked to evaluate the perceptions given in the table on a Likert-type scale of 1 to 5 , where 1 is "strongly agree" and 5 is "strongly disagree". The analysis focuses on the mean response to each question for each type of respondent and tests whether the mean is statistically significantly different from a value of 3 which represents a response of "neutral" on the Likert-type scale at the 5 per cent and 10 per cent levels. In addition, it tests whether the mean of the response for each group is statistically different from the mean response of the other groups for each question.

Table 2

Responses to perception questions - statistical analysis

\begin{tabular}{|l|r|r|r|r|r|r|r|r|r|r|}
\hline \multicolumn{1}{|c|}{ Variables } & $\begin{array}{c}\text { Strongly } \\
\text { agree }\end{array}$ & Agree & Neutral & Disagree & $\begin{array}{c}\text { Strongly } \\
\text { disagree }\end{array}$ & Total & Mean & St. dev \\
\hline Perceptions & 190 & 144 & 149 & 93 & 30 & 606 & $2.39^{\star}$ & 1.21 \\
\hline 1 & 66 & 181 & 133 & 170 & 54 & 604 & 2.94 & 1.17 \\
\hline 2 & 33 & 72 & 120 & 234 & 142 & 601 & $3.63^{\star}$ & 1.13 \\
\hline 3 & 28 & 62 & 118 & 262 & 126 & 596 & $3.66^{\star}$ & 1.07 \\
\hline 4 & 145 & 166 & 122 & 131 & 35 & 599 & $2.57^{\star}$ & 1.23 \\
\hline 5 & & & & & & & \\
\hline
\end{tabular}




\begin{tabular}{|c|c|c|c|c|c|c|c|c|}
\hline 6 & 112 & 241 & 134 & 93 & 25 & 605 & $2.47^{*}$ & 1.08 \\
\hline 7 & 19 & 42 & 160 & 211 & 175 & 607 & $3.79^{*}$ & 1.03 \\
\hline 8 & 172 & 191 & 125 & 81 & 37 & 606 & $2.38^{*}$ & 1.20 \\
\hline 9 & 260 & 231 & 82 & 24 & 10 & 607 & $1.84^{*}$ & 0.92 \\
\hline 10 & 92 & 168 & 136 & 141 & 67 & 604 & $2.87^{\star}$ & 1.25 \\
\hline 11 & 113 & 112 & 30 & 143 & 207 & 605 & $3.36^{*}$ & 1.55 \\
\hline 12 & 22 & 58 & 115 & 214 & 197 & 606 & $3.83^{*}$ & 1.10 \\
\hline 13 & 131 & 208 & 166 & 84 & 14 & 603 & $2.41^{*}$ & 1.05 \\
\hline 14 & 77 & 152 & 194 & 151 & 31 & 605 & $2.85^{\star}$ & 1.09 \\
\hline 15 & 257 & 245 & 68 & 21 & 12 & 603 & $1.82^{*}$ & 0.91 \\
\hline 16 & 154 & 184 & 105 & 92 & 68 & 603 & $2.56^{*}$ & 1.32 \\
\hline 17 & 85 & 158 & 196 & 117 & 48 & 604 & $2.81^{*}$ & 1.14 \\
\hline \multicolumn{9}{|c|}{ Entrepreneurial opportunities } \\
\hline 18 & 127 & 192 & 138 & 114 & 30 & 601 & $2.55^{\star}$ & 1.16 \\
\hline 19 & 96 & 192 & 152 & 138 & 26 & 604 & $2.68^{\star}$ & 1.12 \\
\hline 20 & 120 & 209 & 149 & 87 & 36 & 601 & $2.52^{*}$ & 1.14 \\
\hline 21 & 33 & 118 & 200 & 188 & 62 & 601 & $3.21^{*}$ & 1.05 \\
\hline 22 & 88 & 214 & 178 & 99 & 20 & 599 & $2.58^{\star}$ & 1.03 \\
\hline 23 & 130 & 210 & 109 & 111 & 43 & 603 & $2.55^{\star}$ & 1.22 \\
\hline 24 & 71 & 216 & 159 & 132 & 24 & 602 & $2.70^{*}$ & 1.06 \\
\hline 25 & 25 & 52 & 125 & 241 & 159 & 602 & $3.76^{*}$ & 1.07 \\
\hline 26 & 159 & 242 & 90 & 94 & 20 & 605 & $2.30^{*}$ & 1.12 \\
\hline \multicolumn{9}{|c|}{ Campus entrepreneurship environment } \\
\hline 27 & 41 & 128 & 176 & 186 & 71 & 602 & $3.20^{*}$ & 1.11 \\
\hline 28 & 52 & 108 & 81 & 196 & 164 & 601 & $3.52^{*}$ & 1.29 \\
\hline 29 & 54 & 153 & 141 & 169 & 79 & 596 & $3.11^{*}$ & 1.19 \\
\hline 30 & 42 & 159 & 136 & 176 & 81 & 594 & $3.16^{*}$ & 1.17 \\
\hline 31 & 185 & 273 & 89 & 37 & 19 & 603 & $2.06^{*}$ & 0.99 \\
\hline 32 & 235 & 274 & 70 & 16 & 9 & 604 & $1.82^{*}$ & 0.85 \\
\hline 33 & 218 & 298 & 66 & 16 & 5 & 603 & $1.83^{*}$ & 0.79 \\
\hline 34 & 211 & 273 & 96 & 18 & 5 & 603 & $1.89^{\star}$ & 0.83 \\
\hline 35 & 193 & 233 & 126 & 38 & 7 & 597 & $2.05^{*}$ & 0.95 \\
\hline \multicolumn{9}{|c|}{ South African entrepreneurship environment } \\
\hline 36 & 207 & 227 & 111 & 44 & 16 & 605 & $2.07^{*}$ & 1.03 \\
\hline 37 & 52 & 170 & 242 & 104 & 32 & 600 & $2.82^{*}$ & 0.99 \\
\hline 38 & 79 & 174 & 181 & 125 & 38 & 597 & $2.78^{*}$ & 1.11 \\
\hline 39 & 45 & 179 & 128 & 186 & 59 & 597 & 3.06 & 1.14 \\
\hline 40 & 47 & 157 & 99 & 182 & 109 & 594 & $3.25^{\star}$ & 1.25 \\
\hline
\end{tabular}

Notes: * significant at the 5 per cent level, ! significant at the 10 per cent level.

A preliminary review of these tables reveals the following. On the perception side, respondents agree that entrepreneurship is an honourable occupation and that it plays an important Schumpeterian role by promoting new innovations, technologies and products. They have a positive attitude towards entrepreneurship and have considered it as a career option. Respondents see themselves as risk-takers and perceive entrepreneurship to be a useful way to make money. In contrast and almost in contradiction, respondents seem to think that a large company offers better career prospects. One way of reconciling this is that respondents may think that although being an entrepreneur may yield better income and is a good profession, they feel it may be limiting in terms of future personal growth and 
opportunities. They seem to recognise the more immediate benefits, but are not thinking in an holistic way to see how it could develop into something much larger in the future. A worrying aspect is that they argue that entrepreneurs will do anything for profit which implies the willingness to do something illegal if need be, a level of expediency, and ignores the potential for social entrepreneurship.

Respondents agree that there are many entrepreneurial opportunities in their field. In general, they are positive about their ability to start a business and do not agree that all the good ideas have already been taken. On the contrary, they are on the lookout for business opportunities and have ideas about possible ventures. Respondents feel quite strongly that it is necessary to have contacts to start a business. This is a particularly strong feature of the South African economy both under the previous dispensation of white business networks and the current dispensation of black business networks and empowerment (Luiz, 2002:56)

While they maintain that South Africa is a good country in which to start a business, they are neutral as to whether their local community supports the idea. More importantly, they demonstrate that while they are positive about entrepreneurship, they do not have enough information on how to start a business. For example, they are not aware of government programmes supporting small business startups nor do they know how to gain access to assistance.

\subsection{Perceptions of entrepreneurship broken down by race and gender}

Table 3 breaks down the summary statistics into gender groups and tests whether male and female perceptions are statistically significantly different from each other at the 5 per cent and 10 per cent levels.

Table 3

Perceptions, by gender

\begin{tabular}{|c|c|c|}
\hline \multirow{2}{*}{ Variable } & \multicolumn{2}{|c|}{ Mean } \\
\hline & Male & Female \\
\hline \multicolumn{3}{|l|}{ Perceptions } \\
\hline 1 & 2.09 & 2.74 \\
\hline 2 & 2.93 & 2.95 \\
\hline 3 & 3.60 & 3.65 \\
\hline 4 & 3.66 & 3.68 \\
\hline 5 & $2.50 !$ & $2.67 !$ \\
\hline 6 & 2.46 & 2.45 \\
\hline 7 & 3.91 & 3.66 \\
\hline 8 & 2.16 & 2.61 \\
\hline 9 & 1.79 & 1.86 \\
\hline 10 & 2.91 & 2.83 \\
\hline 11 & 3.43 & 3.30 \\
\hline 12 & 3.93 & 3.74 \\
\hline 13 & 2.25 & 2.55 \\
\hline 14 & 2.69 & 3.00 \\
\hline 15 & 1.81 & 1.77 \\
\hline 16 & 2.58 & 2.54 \\
\hline 17 & 2.94 & 2.68 \\
\hline \multicolumn{3}{|c|}{ Entrepreneurial opportunities } \\
\hline 18 & 2.28 & 2.87 \\
\hline 19 & 2.69 & 2.71 \\
\hline 20 & 2.39 & 2.66 \\
\hline
\end{tabular}




\begin{tabular}{|l|c|l|}
\hline 21 & 3.18 & 3.23 \\
\hline 22 & 2.39 & 2.76 \\
\hline 23 & 2.39 & 2.67 \\
\hline 24 & 2.50 & 2.94 \\
\hline 25 & 3.76 & 3.78 \\
\hline 26 & 2.18 & 2.42 \\
\hline Campus entrepreneurship environment & \\
\hline 27 & 3.22 & 3.17 \\
\hline 28 & 3.59 & 3.45 \\
\hline 29 & 3.08 & 3.16 \\
\hline 30 & 3.26 & 3.07 \\
\hline 31 & $1.97 !$ & $2.13 !$ \\
\hline 32 & 1.72 & 1.89 \\
\hline 33 & $1.75 !$ & $1.87 !$ \\
\hline 34 & 1.86 & 1.92 \\
\hline 35 & $1.95 !$ & $2.09 !$ \\
\hline South African entrepreneurship environment & \\
\hline 36 & 1.93 & $\mathbf{2 . 1 8}$ \\
\hline 37 & 2.85 & 2.81 \\
\hline 38 & $2.69 !$ & $2.86 !$ \\
\hline 39 & $\mathbf{2 . 8 9}$ & 3.22 \\
\hline 40 & 3.09 & 3.41 \\
\hline
\end{tabular}

Notes: Means in bold denote significance at the 5 per cent level, ! denotes significance at the 10 per cent level.

Men seem more inclined to want to start their own businesses as soon as possible than women and are more disposed to consider entrepreneurship as a career option. Men are less prone to find entrepreneurship risky and are also more likely to consider themselves to be risk-takers. Men agree that owning their own business offers great financial potential whilst women are more neutral on the matter.

Men are less certain than women that working for a large company provides better career opportunities and are a lot more certain that they have many good ideas for possible business ventures. Men also perceive more opportunities in their field of study than women and appear more alert to business opportunities. Men are slightly more positive than women regarding their access to assistance as well as being aware of programmes that help people start businesses. There is therefore a distinct gender dimension to entrepreneurship with men being more positively inclined than women, although both genders are in favour of entrepreneurship.

Perceptions can also be broken down by race as shown in Table 44 . Significance is slightly more complicated here as two-way tests are conducted across the four groups. Table 4 indicates only if a mean is different to that of other groups at the 5 per cent level.

Table 4

Perceptions, by race

\begin{tabular}{|l|l|l|l|l|}
\hline \multicolumn{1}{|c|}{ Variable } & \multirow{2}{*}{ African } & \multicolumn{3}{c|}{ Mean } \\
\cline { 3 - 5 } & \multicolumn{5}{|c|}{ Coloured } \\
\hline Perceptions & 2.16 & 2.60 & 2.94 & 2.33 \\
\hline 1 & 2.67 & 3.33 & 3.13 & 3.00 \\
\hline 2 & 3.48 & 3.89 & 3.73 & 3.47 \\
\hline 3 & 3.60 & $3.68^{*}$ & $4.00^{*}$ & $4.00^{*}$ \\
\hline 4
\end{tabular}




\begin{tabular}{|c|c|c|c|c|}
\hline 5 & 2.26 & $3.02^{*}$ & $2.97 !$ & $2.20^{*} !$ \\
\hline 6 & 2.39 & 2.55 & 2.54 & 2.47 \\
\hline 7 & 3.92 & 3.65 & 3.61 & 3.67 \\
\hline 8 & 2.39 & $2.22^{*}$ & $2.72^{*}$ & 2.53 \\
\hline 9 & 1.76 & $1.83^{*}$ & $2.12^{\star}$ & 2.20 \\
\hline 10 & 3.01 & 2.77 & 2.64 & 2.80 \\
\hline 11 & 3.59 & 3.12 & $2.82 !$ & $3.80 !$ \\
\hline 12 & 4.02 & 3.68 & 3.42 & 3.73 \\
\hline 13 & 2.19 & $2.68^{\star}$ & 2.66 & $2.13^{*}$ \\
\hline 14 & 2.60 & 3.15 & 3.03 & 3.13 \\
\hline 15 & 1.87 & $1.63^{\star}$ & $1.92^{*}$ & 1.67 \\
\hline 16 & 2.80 & 2.24 & 2.40 & 2.53 \\
\hline 17 & 2.68 & $3.14^{\star}$ & $2.61^{*}$ & $2.53^{*}$ \\
\hline \multicolumn{5}{|c|}{ Entrepreneurial opportunities } \\
\hline 18 & 2.39 & 2.77 & 2.76 & 2.67 \\
\hline 19 & 2.50 & 3.01 & 2.82 & 2.67 \\
\hline 20 & 2.36 & 2.69 & 2.66 & 2.73 \\
\hline 21 & 3.06 & 3.45 & 3.24 & 3.00 \\
\hline 22 & 2.61 & 2.48 & 2.64 & 2.53 \\
\hline 23 & 2.56 & 2.51 & 2.35 & 2.60 \\
\hline 24 & 2.68 & $2.66^{*}$ & $2.95^{*}$ & 2.80 \\
\hline 25 & 3.70 & 3.87 & 3.73 & 3.80 \\
\hline 26 & 2.08 & $2.44^{\star}$ & $2.93^{\star} !$ & $2.33 !$ \\
\hline \multicolumn{5}{|c|}{ Campus entrepreneurship environment } \\
\hline 27 & 3.19 & 3.15 & 3.28 & 3.40 \\
\hline 28 & 3.35 & $3.87^{\star}$ & $3.40^{*}$ & 3.27 \\
\hline 29 & 3.06 & 3.22 & 3.04 & 3.47 \\
\hline 30 & 3.09 & 3.24 & 3.22 & 3.73 \\
\hline 31 & 1.99 & 2.06 & 2.30 & 2.40 \\
\hline 32 & 1.79 & 1.82 & 1.94 & 1.67 \\
\hline 33 & 1.75 & 1.86 & 2.01 & 1.80 \\
\hline 34 & 1.86 & 1.83 & 2.18 & 2.07 \\
\hline 35 & 1.97 & $2.04^{*}$ & $2.35^{\star}$ & 2.27 \\
\hline \multicolumn{5}{|c|}{ South African entrepreneurship environment } \\
\hline 36 & 1.99 & 2.12 & 2.21 & 2.33 \\
\hline 37 & 2.86 & 2.78 & 2.93 & 2.93 \\
\hline 38 & 2.81 & 2.76 & 2.81 & 2.60 \\
\hline 39 & 3.04 & $3.05^{*}$ & $3.01 !$ & $3.60^{*} !$ \\
\hline 40 & 2.83 & 3.82 & 3.59 & 3.87 \\
\hline
\end{tabular}

Notes: A difference between African and White, Asian or Coloured is shown by numbers highlighted in bold, * indicates a difference between White and Asian or Coloured and! indicates a difference between Asian and Coloured. Caution should be used when interpreting statistics involving the Coloured group as there are so few observations.

The racial results reveal surprising and perhaps counter-intuitive trends. Intuitively one may have expected Asian respondents to be the most positively inclined towards entrepreneurship and Africans the least positively inclined given the fact that the question on parents reveals that Asians have the most entrepreneurially active parents and Africans the least. Yet African respondents think they are more likely to start their own business, followed by Coloureds and Whites, and Asian respondents are least likely. Some 
follow-up interviews revealed that Africans aspire towards new African role models billionaires that have emerged in the postapartheid era of Black Economic Empowerment (BEE) programmes.

Asians had a more hard-nosed attitude having seen how their parents worked long hours and sacrificed to achieve what they had. Asians also a more conservative view of risk. Coloured and African respondents are more likely to consider themselves to be risk-takers than the other two groups but all groups think they are risk-takers. Only African respondents feel that entrepreneurship is an excellent and fast way of generating high incomes. Coloured and African respondents are convinced that entrepreneurs will do almost anything to make a profit, whilst the other two groups are neutral on the matter. African respondents believe most strongly that one needs connections in order to start a business, which again, through further probing, reveals perceptions regarding $\mathrm{BEE}$ and the apartheid favouritism.

White respondents are most likely to think that tertiary education is not necessary in order to be a successful entrepreneur; Africans are least likely to think that. All races believe that there are many opportunities in their major field of study and African respondents are the most positive about this.

African, Coloured and Asian respondents feel that it is too expensive to start one's own business. But African respondents are much more aware than Whites, Coloureds and Asians of state programmes that provide assistance to small business starters and they also feel more positive about the investment climate in South Africa.

\subsection{Perceptions of entrepreneurship broken down by degree of study, parental background, and work experience}

One may consider that students in different degree programmes have differing perceptions of entrepreneurship. To establish whether this is the case the paper breaks down the results into degree of study. Table 5 lists the means for the forty variables by degree of study. Once again significance is more complicated and is only noted if respondents differ at the 5 per cent level.

Table 5

Perceptions by degree of study

\begin{tabular}{|c|c|c|c|c|c|}
\hline \multirow{2}{*}{ Variables } & \multicolumn{5}{|c|}{ Mean } \\
\hline & Commerce & Art & Science & Engineering & MBA \\
\hline \multicolumn{6}{|c|}{ Perceptions of entrepreneurship } \\
\hline 1 & 2.39 & 2.44 & 2.57 & 2.46 & 2.26 \\
\hline 2 & 2.90 & $2.75^{\star}$ & 3.07 & 2.83\# & $3.37^{\star} \#$ \\
\hline 3 & 3.58 & 3.66 & 3.52 & 3.67 & 3.86 \\
\hline 4 & 3.71 & 3.55 & 3.55 & 3.79 & 3.75 \\
\hline 5 & 2.43 & $2.50^{*}$ & $2.71 !$ & $2.42 \#$ & 3.16* !\# \\
\hline 6 & 2.41 & 2.47 & $2.66 !$ & $2.08 ! \#$ & $2.68 \#$ \\
\hline 7 & 3.75 & 3.73 & 3.76 & 4.04 & 3.97 \\
\hline 8 & 2.45 & $2.35^{\star}$ & $2.57 !$ & $2.67 \#$ & $1.91^{\star} ! \#$ \\
\hline 9 & 1.88 & $1.94^{*}$ & $1.88 !$ & $1.92 \#$ & $1.53^{\star} ! \#$ \\
\hline 10 & 2.83 & $2.66^{*}$ & 3.02 & 2.96 & $3.18^{\star}$ \\
\hline 11 & 3.41 & 3.26 & 3.14 & 3.50 & 3.41 \\
\hline 12 & 3.88 & 3.63 & 3.84 & 3.88 & 3.87 \\
\hline 13 & 2.32 & 2.46 & 2.58 & 2.46 & 2.59 \\
\hline 14 & 2.81 & $2.64^{*}$ & $3.00^{*}$ & 2.75 & $3.17^{\star}$ \\
\hline 15 & 1.86 & 1.72 & $1.95 !$ & 1.87 & $1.64 !$ \\
\hline 16 & 2.73 & $2.57^{\star}$ & $2.60 !$ & 2.25 & $2.00^{\star} !$ \\
\hline 17 & 2.71 & $2.67^{*}$ & $2.64 !$ & 2.67\# & $3.47^{\star} ! \#$ \\
\hline
\end{tabular}




\begin{tabular}{|c|c|c|c|c|c|}
\hline \multicolumn{6}{|c|}{ Entrepreneurial opportunities } \\
\hline 18 & 2.53 & 2.55 & 2.70 & 2.33 & 2.68 \\
\hline 19 & 2.62 & $2.63^{*}$ & $2.66 !$ & $2.42 \#$ & 3.14*!\# \\
\hline 20 & 2.39 & $2.70^{\star}$ & $2.81 !$ & 2.04* !\# & 2.74\# \\
\hline 21 & 3.17 & $3.11^{*}$ & 3.16 & 3.30 & $3.50^{\star}$ \\
\hline 22 & 2.61 & 2.65 & 2.36 & 2.63 & 2.50 \\
\hline 23 & 2.29 & $3.07^{\star}$ & $3.10 !$ & 3.46\# & $2.14^{\star} ! \#$ \\
\hline 24 & 2.78 & 2.71 & $2.81 !$ & 2.67 & $2.42 !$ \\
\hline 25 & 3.68 & $3.75^{\star}$ & 3.86 & 3.71 & $4.08^{\star}$ \\
\hline 26 & 2.31 & 2.27 & 2.40 & 2.33 & 2.22 \\
\hline \multicolumn{6}{|c|}{ South African entrepreneurship environment } \\
\hline 36 & 2.10 & $2.23^{*}$ & $2.03 !$ & 2.25\# & $1.70^{\star} ! \#$ \\
\hline 37 & 2.88 & 2.78 & 2.86 & 2.92 & 2.68 \\
\hline 38 & 2.84 & 2.63 & 2.78 & 3.00 & 2.73 \\
\hline 39 & 3.05 & 3.10 & 3.28 & 3.04 & 2.90 \\
\hline 40 & 3.16 & $3.13^{*}$ & 3.41 & 3.46 & $3.66^{\star}$ \\
\hline
\end{tabular}

Notes: $A$ mean in bold indicates a difference between Commerce and any of the other four, $a$ * indicates a difference between Arts and any of the remaining three, a ! indicates a difference between Science and any of the remaining two, and \# indicates a difference between engineering and an MBA.

MBA respondents differ markedly from the rest of the respondents. This may have something to do with their age and race as well as the fact that, unlike the majority of undergraduate respondents, MBA respondents have already obtained professional work experience. Most of the MBA respondents are White and considerably older. They seem to have stronger opinions than the undergraduates and are most likely to think that they will start their own businesses followed by Commerce respondents. MBA respondents are the most open-minded about what constitutes entrepreneurship: they need not be inventors, and businesses can be bought or franchised and still be entrepreneurial. They are also least likely to agree that entrepreneurs will do anything for a profit and this may have something to do with the emphasis placed on ethics, governance and sustainability in MBA programmes since the collapse of Enron.

Generally, all respondents were not exposed to entrepreneurship ideas either at high school or at university, with MBA respondents having the least exposure at high school and the most exposure at university. For MBA respondents, the low exposure to entrepreneurship at school-level may have been due to the curriculum focus, during the period they attended school. High school counsellors may have changed their approach in the more recent past, giving the topic of entrepreneurship more of a focus in the curriculum covered at school. At university level, the nature of the MBA degree results in more exposure, as one would expect.

The results also compare the perceptions of respondents whose parents own businesses to those who do not, parents who are educated to those who are not, and compared respondents who did and did not earn pocket money while they were in school ${ }^{5}$. Respondents whose parents own businesses do not differ greatly from those whose parents do not. Both groups are equally likely to start their own businesses, although respondents whose parents own businesses are more likely to have seriously considered the option.

As regards parental education, respondents differ significantly on only a few variables. The more educated the parents, the less likely they are to start their own businesses (although, on average, all groups agree that they will do so). Respondents whose parents have tertiary education seem more flexible with respect to their definition of entrepreneurship, and are least likely to agree that entrepreneurs are almost always inventors. They are also the least likely to believe that entrepreneurs will do anything to make a profit.

There is no consistent difference in student perceptions when analysing responses related to parents' level of education. Although there 
are significant differences for various questions and groups, there does not appear to be much of a pattern. One is tempted to conclude that parental education may not greatly influence how university students perceive entrepreneurship.

Respondents who did not receive pocket money are more likely to consider themselves to be risk-takers, perhaps out of necessity. Those with pocket money are more inclined to think that entrepreneurship is an honourable profession.

Table 6 characterises the parents' incomes in order to determine whether income has an effect on entrepreneurship perceptions.

Table 6

Perceptions by parental income

\begin{tabular}{|c|c|c|c|c|c|}
\hline \multirow{2}{*}{ Variables } & \multicolumn{5}{|c|}{ Mean } \\
\hline & $<\mathbf{R} 2000$ & R2001-R5000 & R5001- R10 000 & R10 001 - R20 000 & $>\mathrm{R} 20000$ \\
\hline \multicolumn{6}{|c|}{ Perceptions of entrepreneurship } \\
\hline 1 & 2.08 & 2.43 & 2.43 & 2.70\# & $2.32 \#$ \\
\hline 2 & 2.56 & $2.62^{*}$ & $2.84 !$ & $3.34^{*} !$ & $3.14^{*}$ \\
\hline 3 & 3.38 & $3.43^{*}$ & $3.56 !$ & $3.72 !$ & $3.80^{\star}$ \\
\hline 4 & 3.46 & 3.69 & 3.74 & 3.65 & 3.78 \\
\hline 5 & 2.12 & $2.04^{*}$ & $2.68^{\star}$ & $2.81^{*}$ & $2.83^{\star}$ \\
\hline 6 & 2.25 & 2.47 & $2.35 !$ & 2.67! & 2.51 \\
\hline 7 & 3.99 & 3.84 & 3.68 & 3.86 & 3.72 \\
\hline 8 & 2.38 & $2.66^{*}$ & 2.41 & 2.53\# & $2.19 * \#$ \\
\hline 9 & 1.79 & 1.81 & 1.71 & 1.93 & 1.79 \\
\hline 10 & 3.08 & 3.06 & 2.97 & 2.72 & 2.82 \\
\hline 11 & 3.98 & $3.65^{*}$ & $3.13^{\star}$ & 3.30 & $3.12^{*}$ \\
\hline 12 & 4.15 & $4.04^{*}$ & 3.75 & $3.62^{*}$ & 3.78 \\
\hline 13 & 2.07 & $2.10^{*}$ & $2.38 !$ & $2.69 * !$ & 2.56 \\
\hline 14 & 2.49 & $2.449^{*}$ & $2.90^{*}$ & $3.04^{\star}$ & 3.01 \\
\hline 15 & 1.89 & 1.80 & $1.95 !$ & 1.89\# & $1.63 ! \#$ \\
\hline 16 & 2.89 & $2.83^{*}$ & $2.65 !$ & 2.53 & $2.28^{\star} !$ \\
\hline 17 & 2.59 & $2.60^{*}$ & 2.84 & 2.78 & $3.03^{\star}$ \\
\hline \multicolumn{6}{|c|}{ Entrepreneurial opportunities } \\
\hline 18 & 2.38 & 2.41 & 2.56 & 2.86\# & $2.50 \#$ \\
\hline 19 & 2.32 & 2.71 & $2.45 !$ & $2.57 \#$ & 3.01!\# \\
\hline 20 & 2.18 & 2.61 & 2.54 & 2.55 & 2.59 \\
\hline 21 & 2.88 & $2.91^{*}$ & $3.44^{*}$ & 3.22 & $3.33^{*}$ \\
\hline 22 & 2.75 & $2.72^{\star}$ & 2.58 & 2.55 & $2.40^{\star}$ \\
\hline 23 & 2.64 & 2.43 & $2.79 !$ & 2.53 & $2.39 !$ \\
\hline 24 & 2.71 & 2.61 & 2.69 & $2.90 \#$ & $2.59 \#$ \\
\hline 25 & 3.48 & $4.10^{\star}$ & 3.80 & $3.69^{*}$ & 3.92 \\
\hline 26 & 1.98 & 2.30 & 2.30 & 2.41 & 2.34 \\
\hline 35 & 1.95 & 2.00 & 2.15 & 1.97 & 2.05 \\
\hline \multicolumn{6}{|c|}{ South African entrepreneurship environment } \\
\hline 36 & 2.01 & 2.03 & 2.13 & 2.18 & 1.98 \\
\hline 37 & 2.89 & 2.73 & 2.80 & 2.91 & 2.72 \\
\hline 38 & 2.75 & 2.77 & 2.84 & 2.73 & 2.87 \\
\hline 39 & 3.03 & $2.94^{*}$ & 3.06 & $3.36^{\star} \#$ & $2.88 \#$ \\
\hline 40 & 2.84 & $2.85^{*}$ & $3.32^{\star}$ & $3.33^{\star}$ & $3.51^{*}$ \\
\hline
\end{tabular}


Notes: A mean in bold indicates a difference between an income of less than R2000 and any of the other four, * indicates a difference between an income of between R2001 and R5000 and any of the remaining three, ! indicates a difference between an income between R5001 and R10 000 and any of the remaining two, and \# indicates a difference between an income between R10 001 and R20 000 and an income greater than R20 000.

Respondents from both the poorest and richest households are most likely to think that they will start their own businesses. As discussed above, it may be that poorer respondents are thinking about more basic enterprises whilst richer ones are thinking about innovative startups. Yet poorer respondents are more inclined to think that business owners will do anything to make a profit while believing that it is not necessarily true that they may earn more money working for a company.

Respondents in the lowest two income groups are least likely to feel that it is too risky to start their own business and are correspondingly most likely to believe that they are risk-takers. Interestingly, respondents in the highest two income groups are least likely to believe that entrepreneurship is a financially viable option while those in the lowest two income groups are most likely to believe this.

However, all the respondents, except those in the highest income group would prefer to work for a large company, believing that there would be better career opportunities. Only the highest income group disagreed with that statement. This suggests that poorer respondents may see entrepreneurship as a necessity, perhaps indicating some doubt about their ability to find a job working for a business. On the other hand, the richest respondents may have more confidence about finding jobs in large companies and may see entrepreneurship as more of a risky choice. Respondents from these differing income groups may have different perceptions about what constitutes owning their own business. Richer respondents are thus less likely to believe that owning a franchise or buying a business is not entrepreneurship.

The results obtained from breaking down responses by income group are closely related to those broken down by race group when acknowledging that respondents from the wealthiest income groups are likely to be White while those from the poorest group are likely to be Black. Overall, respondents from the poorest two groups appear to be the most positive about starting their own businesses and also appear to have access to more information.

Table 7 shows the differences between respondents who had a part-time job whilst at school or at university and those who did not as well as the difference between those who took business related subjects and those who did not.

Table 7

Perceptions by job background and access to business courses

\begin{tabular}{|c|c|c|c|c|c|c|}
\hline \multirow{3}{*}{ Variables } & \multicolumn{6}{|c|}{ Mean } \\
\hline & \multicolumn{2}{|c|}{ School job } & \multicolumn{2}{|c|}{ University job } & \multicolumn{2}{|c|}{ Business subjects } \\
\hline & Yes & No & Yes & No & Yes & No \\
\hline \multicolumn{7}{|c|}{ Perceptions of entrepreneurship } \\
\hline 1 & 2.21 & 2.57 & 2.31 & 2.51 & 2.47 & 2.36 \\
\hline 2 & 2.94 & 2.97 & 3.09 & 2.83 & 2.92 & 3.01 \\
\hline 3 & 3.73 & 3.54 & 3.71 & 3.55 & 3.59 & 3.70 \\
\hline 4 & 3.74 & 3.60 & 3.74 & 3.61 & 3.67 & 3.68 \\
\hline 5 & 2.75 & 2.48 & 2.76 & 2.44 & 2.49 & 2.71 \\
\hline 6 & 2.40 & 2.48 & 2.46 & 2.46 & 2.48 & 2.45 \\
\hline 7 & 3.87 & 3.73 & 3.79 & 3.80 & 3.76 & 3.83 \\
\hline 8 & 2.15 & 2.54 & 2.25 & 2.51 & 2.46 & 2.31 \\
\hline 9 & 1.79 & 1.86 & 1.82 & 1.86 & 1.91 & 1.73 \\
\hline 10 & 3.08 & 2.70 & 2.97 & 2.77 & 2.83 & 2.92 \\
\hline 11 & 3.29 & 3.42 & 3.26 & 3.47 & 3.32 & 3.44 \\
\hline
\end{tabular}




\begin{tabular}{|c|c|c|c|c|c|c|}
\hline 12 & 3.91 & 3.79 & 3.77 & 3.87 & 3.86 & 3.76 \\
\hline 13 & 2.30 & 2.49 & 2.44 & 2.37 & 2.36 & 2.52 \\
\hline 14 & 2.87 & 2.85 & 2.92 & 2.81 & 2.84 & 2.88 \\
\hline 15 & 1.61 & 1.93 & 1.73 & 1.83 & 1.83 & 1.75 \\
\hline 16 & 2.49 & 2.63 & 2.40 & 2.71 & 2.71 & 2.34 \\
\hline 17 & 3.06 & 2.67 & 3.02 & 2.65 & 2.66 & 3.06 \\
\hline \multicolumn{7}{|c|}{ Entrepreneurial opportunities } \\
\hline 18 & 2.37 & 2.68 & 2.57 & 2.55 & 2.55 & 2.59 \\
\hline 19 & 2.77 & 2.63 & 2.79 & 2.60 & 2.58 & 2.84 \\
\hline 20 & 2.44 & 2.59 & 2.60 & 2.44 & 2.44 & 2.60 \\
\hline 21 & 3.28 & 3.14 & 3.20 & 3.20 & 3.23 & 3.18 \\
\hline 22 & 2.50 & 2.59 & 2.50 & 2.61 & 2.60 & 2.53 \\
\hline 23 & 2.35 & 2.65 & 2.47 & 2.58 & 2.36 & 2.77 \\
\hline 24 & 2.55 & 2.84 & 2.62 & 2.79 & 2.77 & 2.67 \\
\hline 25 & 3.87 & 3.70 & 3.76 & 3.78 & 3.67 & 3.89 \\
\hline 26 & 2.38 & 2.26 & 2.23 & 2.40 & 2.27 & 2.32 \\
\hline 35 & 1.95 & 2.06 & 1.95 & 2.09 & 1.99 & 2.12 \\
\hline \multicolumn{7}{|c|}{ South African entrepreneurship environment } \\
\hline 36 & 1.90 & 2.16 & 1.98 & 2.12 & 2.09 & 2.05 \\
\hline 37 & 2.68 & 2.94 & 2.70 & 2.95 & 2.80 & 2.87 \\
\hline 38 & 2.77 & 2.82 & 2.74 & 2.86 & 2.79 & 2.83 \\
\hline 39 & 2.94 & 3.13 & 3.04 & 3.03 & 3.02 & 3.14 \\
\hline 40 & 3.34 & 3.16 & 3.30 & 3.19 & 3.22 & 3.31 \\
\hline
\end{tabular}

Respondents with early exposure to financial responsibility are more likely to think that they will start their own businesses. They are also more flexible on what constitutes an entrepreneur as well as slightly less inclined to think that entrepreneurs would do anything for a profit. It thus comes as no surprise that these are also the respondents who are more likely to have considered entrepreneurship as a career option and are more likely to consider themselves to be risk-takers. They are more convinced that entrepreneurship is an honourable profession and less likely to believe that their career prospects are better at a large company. They are also more prone to believe that they have many ideas for business ventures.

Respondents with part-time jobs at university are also generally more positive about entrepreneurship than those without jobs and are less likely to think that a tertiary education is necessary to be an entrepreneur.

Generally, respondents who did not take any business classes seem more optimistic about entrepreneurship. Probing revealed that the perceptions of these respondents had an element of romanticism; many were unaware of what entrepreneurial success and commitment really requires. They also seem less inclined to believe that they would have better career prospects working for another company. The reason may be that business classes bias students away from entre-preneurship given that there is not much focus on entrepreneurial content and tend to train students for the existing labour market that is dominated by larger corporations.

\section{5}

\section{Conclusion}

The results extracted from this sample of 609 South African students generally reveal that respondents have a very positive attitude towards entrepreneurship. Over 83 per cent of the respondents view entrepreneurship as an honourable profession and respect people who are entrepreneurs. More than half intend starting their own business as soon as possible and see themselves as risk-takers. However, delving further into these results illustrate distinct gender and racial differences with men 
generally more positively disposed towards entrepreneurship whilst Africans are the most positive and Asians the least positive. Degree of study, parental income, student work and financial experience all appear to affect perceptions of entrepreneurship. The results reinforce the earlier literature review which emphasised the importance of both individual and social characteristics with regard to entrepreneurial attitudes.

Given these generally favourable results, the paper is left with the puzzling question as to why South Africa performs so poorly on international entrepreneurship rankings? One explanation could be that the sample of university students is automatically more entrepreneurial than less qualified South Africans. However, this contradicts available evidence that university students tend to seek employment in the existing corporate sector. It is evident that although respondents believe entrepreneurship to be an honourable occupation and can imagine themselves running their own businesses, they are nonetheless attracted by the employment and financial security available in large corporations. Indeed, over 40 per cent of the sample admits that they would prefer to work in large companies because of better career prospects with a further third being neutral, and less than 28 per cent disagreeing with the desire to work for a large company. It could be that currently students have a more idealistic view (as one would expect at that age), but when they enter the 'real' world then the realities become enmeshed with risk aversion and overshadow these perceptions, rendering entrepreneurial activities largely defunct.

\subsection{Limitations and recommendations for future research}

This paper uses a cross sectional approach to entrepreneurial attitudes and behaviours and as such cannot look at the dynamics of these perceptions nor can it determine any causal influences. A longitudinal study which follows these respondents over time as they leave university and enter the workforce would yield useful insights about how their perceptions change and how their perceptions match up with their actual employment choices. Furthermore, there have been great advances in the area of behavioural and experimental economics which would be useful for testing some of these results. An obvious extension would be the analysis of risk aversion through experiments and the use of real world incentives.

\subsection{Study implications}

The paper demonstrates that socio-economic, demographic, cultural and institutional variables are associated with the entrepreneurial attitudes of individuals. This has interesting potential implications for the policy realm where the South African government has spent enormous resources in trying to stimulate entrepreneurship with limited success (Herrington et al., 2009:15). Some of the characteristics which have revealed themselves to be significant include race and gender and these are path dependent which government policy cannot alter, but it can play a role in underwriting risk through various types of affirmative action. For example, the research shows that the level of study and the degree being pursued matters and this does allow for policy intervention. Furthermore, the way in which individuals think of themselves and their abilities is itself influenced by institutional factors and these are subject to intervention although it is a slow process (see Luiz, 2009:59). A more holistic approach to entrepreneurship and policy is thus warranted.

\section{Acknowledgement}

The authors gratefully acknowledge the financial support of ERSA.

\section{Endnotes}

1 Total Early-stage Entrepreneurial Activity (TEA) index indicates the prevalence of business startups (or nascent entrepreneurs) and new firms in the adult (18 to 64 years of age) population - in other words, it captures the level of dynamic entrepreneurial activity in a country. 
2 Students completing the matriculation year obtain a high school completion certificate. Tertiary education refers to post school higher education.

3 See Appendix A for a list of question numbers and their assigned variables. Due to space constraints, these are not included in the tables in this section.

4 Given South Africa's history of exclusionary racial estates which also applied to economic and educational opportunities, it makes sense for us to test these perceptions using the official racial classification of White, African/Black, Asian and Coloured. This was the classification employed under apartheid and it is being used by the current government to promote a form of Affirmative Action.

5 We do not present these results because of space constraints, but the results are available from the author.

\section{References}

AHWIRENG-OBENG, F. 2006. Entrepreneurship in Africa. In Luiz.J (ed.) Managing business in Africa. Cape Town: Oxford University Press.

AYYAGARI, M., BECK, T. \& DEMIRGUC-KUNT, A. 2007. Small and medium enterprises across the globe. Small Business Economics. 29:415-434.

BANERJEE, A., GALIAN. S., LEVINSOHN, J., MCLAREN, Z. \& WOOLARD, I. 2008. Why has unemployment risen in the new South Africa. Economics of Transition. 16(4):715-740.

BOSMA, N. \& LEVIE, J. 2009. Global entrepreneurship monitor: 2009 global report. [Online] Available at: http://www.gemconsortium.org/download.asp?fid=1055

BURGER, L., MAHADEA, D. \& O'NEILL, C. 2004. Perceptions of entrepreneurship as a career option in South Africa: an exploratory study among grade 12 learners. South African Journal of Economic and Management Sciences. 7(2):187-205.

CARTON, R.B., HOFER, C.W. \& MEEKS, M.D. 1998. The Entrepreneur and Entrepreneurship: Operational Definitions of Their Role in society. [Online] Available at: http://sbaer.uca.edr?research/1998/ICSB/k004.htm.

DAVIDSSON, P. \& WIKLUND, J. 1997. Values, beliefs and regional variations in new firm formation rates. Journal of Economic Psychology. 18:179-199.

DEPARTMENT OF TRADE AND INDUSTRY 2008. Annual review of small business in South Africa. [Online] Available at: http://www.thedti.gov.za/publications/Annual_Review.pdf. [Accessed 2010-11-29].

HAYTON, C., GEORGE, G. \& ZAHRA, S. 2002. National culture and entrepreneurship: a review of behavioural research. Entrepreneurship Theory and Practice. Summer:33-52.

HERRINGTON, M., KEW, J. \& KEW, P. 2009. Tracking entrepreneurship in South Africa: a GEM perspective. Cape Town: GEM.

KINGDON, G.G. \& KNIGHT, J. 2004. Unemployment in South Africa: The nature of the beast. World Development. 32(3):391-408.

KURATKO, D.F. \& HODGETTS, R.M. 2001. Entrepreneurship, a contemporary approach $\left(5^{\text {th }}\right.$ ed.) Orlando: Harcourt Publishers.

LEFF, N. H. 1979. Entrepreneurship and economic development: the problem revisited. Journal of Economic Literature. XVII:46-64.

LOUW, L., VAN EEDEN, S.M., BOSCH, J.K. \& VENTER, D.J.L. 2003. Entrepreneurial traits of undergraduate students at selected South African tertiary institutions. International Journal of Entrepreneurial Behaviour and Research. 9(1):5-26.

LUIZ, J. 2002. Small business development, entrepreneurship and expanding the business sector in a developing economy: the case of South Africa. Journal of Applied Business Research. 18(2):53-68.

LUIZ, J. 2009. Institutions and economic performance: implications for African development. Journal of International Development. 21:58-72.

MORRISON, A. 2000. Entrepreneurship: what triggers it? International Journal of Entrepreneurial Behaviour and Research. 6(2):59-71.

MUELLER, S. \& THOMAS, A. 2000. Culture and entrepreneurial potential: a nine county study of locus of control and innovativeness. Journal of Business Venturing. 16:51-75.

NAUDE, W. 2011. Entrepreneurship is not a binding constraint on growth and development in the poorest countries. World Development. 39(1):33-44. 
RODRIK, D. 2008. Understanding South Africa's economic puzzles. Economics of Transition. 16(4):769797.

SCHUMPETER, J.A. 1934. The theory of economic development. Boston: Harvard University Press.

SIMMONS, C. 1998. The spirit of the graduate entrepreneur. [Online] Available at: http://www.soton.ac.uk/ infoserv/pubaff/newrep/vol16/no20stud.html.

STATISTICS SA. 2010. Key indicators. [Online] Available at: http://www.statssa.gov.za/keyindicators/keyindicators.asp. [Accessed 2010-11-29].

URBAN, B. (ed.) 2008. Frontiers in Entrepreneurship. Johannesburg: Heinemann Publishers.

URBAN, B. 2010. Competitive strategies for technology entrepreneurs: links to environmental dynamism and hostility. International Journal of Entrepreneurship and Innovation. 11(1):69-77.

VAN PRAAG, C.M. VERSLOOT, P.H. 2007. What is the value of entrepreneurship? A review of recent research. Small Business Economics. 29:351-382. 


\section{Appendix 1: List of question numbers and their assigned variables}

\begin{tabular}{|c|c|}
\hline Number & Variable \\
\hline \multicolumn{2}{|c|}{ Perceptions of Entrepreneurship } \\
\hline 1 & Wants to start own business \\
\hline 2 & Entrepreneurs are almost always inventors \\
\hline 3 & Buying a business is not entrepreneurship \\
\hline 4 & Owning a franchise is not entrepreneurship \\
\hline 5 & Entrepreneurs will do anything for profit \\
\hline 6 & Entrepreneurs are largely responsible for new innovations, technologies and products \\
\hline 7 & Can earn more money working for someone else \\
\hline 8 & Has seriously considered entrepreneurship as career option \\
\hline 9 & Academic institutions should encourage students to consider entrepreneurship \\
\hline 10 & Too busy with classes to consider starting own business \\
\hline 11 & Parents are entrepreneurs \\
\hline 12 & Too risky to start own business \\
\hline 13 & Is a risk-taker \\
\hline 14 & Entrepreneurship is a good way to make lots of money \\
\hline 15 & Entrepreneurship is an honourable profession \\
\hline 16 & A tertiary education is not necessary to be an entrepreneur \\
\hline 17 & Prefers to work for a large company, better career prospects \\
\hline \multicolumn{2}{|c|}{ Entrepreneurial Opportunities } \\
\hline 18 & Has many ideas for business ventures \\
\hline 19 & Too expensive to start own business \\
\hline 20 & There are many entrepreneurial opportunities in student's area of study \\
\hline 21 & Entrepreneurial ventures are mainly limited to business ideas \\
\hline 22 & Has good understanding of intellectual property \\
\hline 23 & Understands equity finance \\
\hline 24 & Constantly alert to business opportunities \\
\hline 25 & All the good ideas have been taken \\
\hline 26 & Need connections to start a business \\
\hline \multicolumn{2}{|c|}{ Campus entrepreneurship environment } \\
\hline 27 & Students are encouraged to pursue entrepreneurship ventures \\
\hline 28 & High school counsellor mentioned entrepreneurship as career option \\
\hline 29 & Examples of how science and technology are key to business are included in class examples \\
\hline 30 & Entrepreneurial or business related examples are included in classes \\
\hline 31 & Having a mentor would help \\
\hline 32 & A small seed grant would encourage entrepreneurship \\
\hline 33 & More business sector interaction would encourage entrepreneurship \\
\hline 34 & $\begin{array}{l}\text { Private sector support for student entrepreneurs would result in more university based business } \\
\text { start-ups. }\end{array}$ \\
\hline 35 & $\begin{array}{l}\text { A programme to defer student loan payments for student entrepreneurs would encourage more } \\
\text { students to pursue a business venture after graduation }\end{array}$ \\
\hline \multicolumn{2}{|c|}{ South African entrepreneurship environment } \\
\hline 36 & South Africa is an excellent country to start a business. \\
\hline 37 & My local community supports entrepreneurs \\
\hline 38 & It would be very difficult to raise the money needed to start a new business in South Africa \\
\hline 39 & I know how to have access to the assistance I would need to start a new business. \\
\hline 40 & I am aware of programmes the state provides to help people start businesses \\
\hline
\end{tabular}

